\title{
Formação de professores da educação infantil para um cuidar e educar humanizadores
}

\author{
Priscila da Silva Rocha ${ }^{1}$ \\ Amanda Valiengo ${ }^{2}$
}

SILVA, José Ricardo et al. (Org.). Educação de bebês: cuidar e educar para o desenvolvimento humano. São Carlos: Pedro \& João Editores, 2018.

O livro Educação de bebês: cuidar e educar para o desenvolvimento humano apresenta, nos nove capítulos iniciais, um diálogo entre a Teoria Histórico-Cultural (THC), o desenvolvimento humano e a formação de professores e professoras no contexto da creche. A obra possui dez capítulos de autoria dos organizadores e dos discentes do Programa de PósGraduação em Educação da Faculdade de Filosofia e Ciências da UNESP do campus Marília que participaram em 2016 da disciplina "Implicações Pedagógicas da Teoria HistóricoCultural e a Educação dos bebês". Os nove primeiros capítulos compõem a primeira parte do livro intitulada Perspectiva histórico-cultural no cuidado e educação dos bebês. Somente o último capítulo compreende a segunda parte intitulada Um outro olhar, com um capítulo que trata sobre o desenvolvimento infantil em uma perspectiva Reichiana.

A obra tem como organizadores: José Ricardo Silva, doutor em Educação pela Faculdade de Ciências e Tecnologias da UNESP; Regina Aparecida Marques de Souza, professora do Programa de Pós-Graduação em Educação da UFMS; Suely Amaral Mello, professora do Programa de Pós-Graduação em Educação da Faculdade de Filosofia e Ciências da UNESP e Vanilda Gonçalves de Lima, docente do Curso de Pedagogia da Faculdade de Marília.

A temática abordada no livro é relevante para a reflexão de profissionais da área da Educação Infantil, pois trata de aspectos pedagógicos do cuidar e educar na creche. A obra chama a atenção para o papel do professor de Educação Infantil trazendo conceitos

\footnotetext{
${ }^{1}$ Mestranda em Educação pela Universidade Federal de São João del-Rei/MG. E-mail: prisr@ bol.com.br

${ }^{2}$ Pós-doutora pela Universidade Federal do Espírito Santo. Professora Adjunta da Universidade Federal de São João Del-Rei/MG, no Departamento de Ciências da Educação e no Mestrado em Educação. E-mail: amanda.valiengo@ufsj.edu.br
} 
fundamentais sobre o desenvolvimento da criança até os três anos de idade, sendo um importante instrumento para os interessados no campo.

Nóvoa (1995, p. 25) destaca que “A formação não se constrói por acumulação (de cursos, de conhecimentos ou de técnicas), mas sim por meio de um trabalho de reflexividade crítica sobre as práticas e de (re)construção permanente de uma identidade pessoal”. Esse livro pode auxiliar nessa reflexividade da ação e da prática docente, tendo como foco a formação de professores e professoras da creche.

No prefácio, Paulo Sérgio Fochi afirma que a Educação Infantil, mais especificamente os temas relativos aos cuidados e à educação de bebês, são negligenciados na formação inicial. Por isso essa obra também pode contribuir para o campo acadêmico e profissional, na formação inicial e continuada, uma vez que discute tais temas ainda carentes de aprofundamento.

O primeiro capítulo, Contribuições da teoria histórico-cultural para a compreensão do bebê como sujeito ativo, José Ricardo Silva inicia com uma discussão sobre a concepção de bebê como sujeito ativo que se desenvolve, destacando a mudança das funções psíquicas elementares, existentes no nascimento da criança, para as superiores (a comunicação, a memória, o pensamento e a atenção), evidenciando, nesse processo, a dependência do adulto, a relação com o outro e com o meio. O desenvolvimento das funções superiores é o que nos caracterizam como seres humanos e a apropriação da cultura construída historicamente é o que humaniza o sujeito. Na segunda parte do capítulo, o autor destaca o papel do professor e da professora com o bebê ativo, mostrando que o docente precisa organizar o tempo, o espaço e promover condições para o desenvolvimento infantil.

Ainda na perspectiva da criança como sujeito ativo, Bárbara Cibelli da Silva Monteagudo, no segundo capítulo, Crianças independentes e autônomas, o papel do professor e da professora no desenvolvimento dos bebês nas creches, apresenta ao leitor a concepção de criança que norteia a THC e a importância da aprendizagem para o desenvolvimento humano. Destaca também os aspectos do triplo protagonismo nesse processo: "criança que olha e ouve e toca, professor e professora que organizam o trabalho pedagógico e os objetos que vamos apresentando às crianças de forma direta e indireta.” (p. 55). No final do capítulo, a comunicação dos bebês, sua relação com os objetos e a organização dos espaços são evidenciadas para compreender o desenvolvimento da linguagem. 
A Lei Geral do Desenvolvimento enunciada por Vigotski (2010), afirma que as funções psíquicas superiores se formam na relação com o outro. Para que elas se transformem de elementar para superiores, é necessário que os adultos criem necessidades nas crianças para que aprendam e, consequentemente se desenvolvam. Vigotski é citado pelos autores dos capítulos da obra para a reflexão em torno do processo do desenvolvimento desde o primeiro ano de vida. Em vários capítulos, são apresentadas as atividades principais até os três anos.

A primeira atividade, no primeiro ano de vida é a comunicação emocional. Nesse momento, o bebê aprende a se comunicar com o adulto por meio do olhar, dos sorrisos, dos movimentos dos membros, dos balbucios. Convivendo com o adulto como parceiro mais experiente, o bebê vai criando necessidades de comunicação também por meio da linguagem verbal e necessidade de conhecer os objetos da cultura humana, assim a criança passa a dar atenção aos objetos (segunda atividade principal). A manipulação de objetos impulsiona o desenvolvimento nesse período de vida. E, ao final dos três anos, "a criança inicia a formação da função simbólica da consciência a partir das ações com objetos e por meio das representações sociais" (p. 107) configurando a terceira atividade principal, a do brincar.

O livro evidencia as atividades principais que promovem o desenvolvimento das crianças de até três anos. Os capítulos três e quatro, Algumas especificidades na constituição da inteligência e da personalidade na primeira infância, de Neire Márcia da Cunha e Selma Aparecida Ferreira da Costa e A atividade principal no processo de educação de bebês, de Vanilda Gonçalves de Lima apresentam conceitos abordados pela teoria de Vigotski. Os conceitos de idade psicológica, estrutura e dinâmica interna do desenvolvimento, atividade principal, tipos de linguagem, ruptura e vivência são pressupostos e premissas apresentados pelas autoras. Esses conceitos são importantes para a problematização da teoria e para o entendimento do desenvolvimento humano. As autoras expuseram esses conceitos de forma clara e agradável de ler, permitindo a compreensão da teoria e salientando a importância do papel do professor enquanto sujeito mediador das atividades buscando o desenvolvimento da criança.

Vanilda Gonçalves de Lima se debruça na temática trazendo a importância da compreensão das atividades para o desenvolvimento de uma prática docente que reconheça a criança como sujeito ativo e uma atuação pedagógica atrelada à organização de condições necessárias ao desenvolvimento. Atividade principal se caracteriza como a atividade que impulsiona o desenvolvimento da criança. A autora também traz as aproximações entre a Teoria Histórico-Cultural e o Instituto Pikler-Lóczy, dentre elas as relações entre os adultos e 
as crianças; e a valorização da atividade autônoma. Esse capítulo instiga o leitor a querer conhecer mais as relações entre a THC e as ideias do Instituto Pikler que podem auxiliar práticas pedagógicas humanizadoras.

Os professores e professoras da Educação Infantil precisam compreender o processo de desenvolvimento da criança para elaborar sua prática. Compreender o desenvolvimento humano a partir das concepções da THC é uma oportunidade de pensar a prática docente. Martinez (2017) afirma que a instituição educativa é um contexto constituído por pessoas e que ao pensarmos nesse contexto precisamos reconhecer o lugar dos professores e das professoras, refletindo sobre como o docente se coloca diante das crianças.

Nos quatro capítulos seguintes, O espaço para bebês e crianças pequenas, de Adriane Pereira Borges Scudeler; O tempo dos bebês na Educação Infantil, escrito por Marcelo Campos Pereira; O bebê e o desenvolvimento da fala, de Marcia Regina dos Reis e Formação de atitudes leitoras nos três primeiros anos de vida: influências e possibilidades, de Yngrid Karolline Mendonça Costa e Kenia Adriana de Aquino Modesto-Silva; os autores apresentam o espaço, o tempo, o desenvolvimento da fala e o livro infantil como pontos centrais para a discussão na formação de professores.

Discorrem sobre as atitudes dos docentes da Educação Infantil relacionadas à organização do espaço e do tempo para promover o desenvolvimento infantil, destacam o papel do adulto para o desenvolvimento da fala e propõem o livro como objeto cultural que pode ser inserido nas práticas educativas da creche. Nesses capítulos, podemos perceber o papel da intencionalidade, da organização e da interferência na mediação do professor. Eles permitem uma reflexão do fazer docente, pois enfatizam as relações no cotidiano da Educação Infantil articulando ao desenvolvimento das crianças e ao papel do adulto.

Regina Aparecida Marques de Souza e Suely Amaral Mello, autoras do nono capítulo, $O$ desenvolvimento cultural na infância de 0 a 3 anos: entre o cuidado e a educação, apresentam um diálogo sobre o cuidar e o educar. Para expor a temática, as autoras remetemse às concepções de criança. Destacam que "A velha concepção de criança como incapaz se esconde num discurso sobre a fragilidade da criança pequena" (p. 211). Contrapondo a essa visão de criança, as autoras evidenciam a concepção abordada pela THC, na qual a "criança é capaz de viver experiências desde que nasce e de atribuir um sentido a elas" (p. 213). Nesse capítulo, as autoras articulam os pressupostos da teoria com as atividades do cuidar e do educar, e retomam as ideias de desenvolvimento discutido pelos autores dos capítulos anteriores.

Revista Devir Educação, Lavras, vol.3, n.2, p.172-176 jul./dez., 2019. 
O texto que encerra a obra, de autoria de Susana Zaniolo Scotton, denominado $A$ criança e seu desenvolvimento até o terceiro ano: implicações para a esfera da educação escolar apresenta um olhar para o desenvolvimento humano a partir da Psicologia Reichiana. A autora apresenta alguns pressupostos dessa perspectiva corporal para compreender o desenvolvimento infantil. Destaca o lugar do corpo biológico na articulação com o fenômeno psíquico. Apesar de utilizar uma concepção teórica diferente dos demais capítulos do texto, também aborda sobre a formação e a atuação docente.

Nóvoa (1995, p. 28) declara que a formação passa pela experimentação, pela reflexão crítica e por processos de investigação articulados com as práticas educativas, portanto o livro Educação de bebês: cuidar e educar para o desenvolvimento humano é um importante instrumento para reflexão dos professores e das professoras da Educação Infantil. Diante disso, torna-se leitura oportuna para os profissionais da área. É uma obra importante para a prática docente porque reúne em um único livro um rico acervo de discussões relacionadas ao desenvolvimento infantil evidenciando o agir docente.

\section{Referências}

NÓVOA, António. Formação de professores e profissão docente. In: NÓVOA, António (Org.). Os professores e a sua formação. Lisboa: Nova Enciclopédia, Publicações Dom Quixote, 1995.

MARTINEZ, Andréia Pereira de Araújo. O lugar da professora e do professor em uma proposta pedagógica promotora de desenvolvimento. In: COSTA, S. A.; MELLO, S. A. (Org.). Teoria histórico-cultural na educação infantil: conversando com professoras e professores. Curitiba: Editora: CRV, 2017.

VIGOTSKI, Lev Semenovich. A construção do pensamento e da linguagem. 2. ed. Tradução: Paulo Bezerra. São Paulo: Martins Fontes, 2010. 